\title{
Las nuevas formas de vivienda de alquiler social en Cataluña (2015-2020): un análisis desde el marco teórico europeo
}

\author{
Jordi Bosch Meda \\ Universitat Politècnica de Catalunya \\ jordi.bosch@hotmail.es
}

Recibido: octubre de 2020
Aceptado: enero de 2021
Publicado: marzo de 2021

\section{Resumen}

El objetivo de este artículo es analizar las nuevas formas de vivienda de alquiler social que contempla la normativa catalana aprobada a partir de 2015 hasta inicios de 2020 desde seis variables: el precio del alquiler, la forma de adjudicación, los requisitos de las personas destinatarias, la financiación pública del instrumento, la titularidad del inmueble y el tiempo durante el cual la vivienda será de alquiler social. El estudio constata que: (i) todas estas nuevas viviendas, excepto las de alquiler social voluntario u obligatorio, encajarían conceptualmente en las definiciones menos exigentes, puesto que reúnen los requisitos de precio, normas de adjudicación y condiciones socioeconómicas de las personas beneficiarias; (ii) y, en cambio, solamente las obtenidas mediante tanteo y retracto o expropiación tendrían cabida en las definiciones más exigentes, ya que son las únicas cuya titularidad recae sobre el sector público o el tercer sector.

Palabras clave: vivienda; política de vivienda; vivienda social; vivienda de alquiler social; Cataluña

Resum. Les noves formes d'habitatge de lloguer social a Catalunya (2015-2020): una anàlisi des del marc teòric europeu

L'objectiu d'aquest article és analitzar les noves formes d'habitatge de lloguer social que preveu la normativa catalana aprovada a partir de 2015 fins a l'inici de 2020 des de sis variables: el preu de lloguer, la forma d'adjudicació, els requisits de les persones destinatàries, el finançament públic de l'instrument, la titularitat de l'immoble i el temps durant el qual l'habitatge serà de lloguer social. L'estudi constata que: (i) tots aquests nous habitatges, excepte els de lloguer social voluntari o obligatori, encaixarien conceptualment en les definicions menys exigents, ja que reuneixen els requisits de preu, normes d'adjudicació i condicions socioeconòmiques de les persones beneficiàries; (ii) i, en canvi, només els obtinguts mitjançant tempteig i retracte o expropiació tindrien cabuda en les definicions més exigents, ja que són els únics de titularitat pública o del tercer sector.

Paraules clau: habitatge; política d'habitatge; habitatge social; habitatge de lloguer social; Catalunya 
Résumé. Les nouvelles formes de logements locatifs sociaux en Catalogne (2015-2020): une analyse du cadre théorique européen

Le but de cet article est d'analyser les nouvelles formes de logement social locatif que la réglementation catalane approuvée de 2015 à début 2020 envisage, et ce à partir de six variables : le prix de location, la forme d'attribution, les exigences des bénéficiaires, le financement public de l'instrument, le type de fournisseur de logement et le temps pendant lequel ce dernier sera à loyer modéré. L'étude constate que: (i) toutes ces nouveaux logements, à l'exception de ceux à loyer social volontaire ou obligatoire, s'inscriraient conceptuellement dans les définitions moins exigeantes car ils répondent aux exigences de prix, aux règles d'attribution et aux conditions socioéconomiques des bénéficiaires; (ii) et, d'autre part, seuls les logements obtenus par droit de premier refus et de rétractation ou expropriation auraient une place dans les définitions les plus exigeantes car ce sont les seuls dont la propriété revient au secteur public ou au troisième secteur.

Mots-clés : logement; politique du logement; logement social; logement social locatif; Catalogne

Abstract. New forms of social rental housing in Catalonia (2015-2020): An analysis from the European theoretical framework

The aim of this article is to analyze the new forms of social rental housing that the Catalan legislation passed from 2015 to early 2020 using six variables: the rental price, the allocation system; the target group; the public funding arrangements; the type of housing provider; and the time during which the dwelling is available for social rent. The study finds that: (i) these new housing units, except voluntary or compulsory social rental dwellings, fit conceptually into less demanding definitions of these dwellings since they meet the requirements of price, socioeconomic conditions of the beneficiaries, and the existence of allocation rules, and (ii) only those obtained by right of first refusal and repurchase or through expropriation have a place in the most demanding social housing definitions given that they are the only dwellings owned by the public sector or the third sector.

Keywords: housing; housing policy; social housing; social rental housing; Catalonia

\section{Sumario}
1. Introducción
4. Conclusiones y discusión
2. Marco teórico
Referencias bibliográficas

3. Las nuevas formas de fomento

del alquiler social en Cataluña

\section{Introducción}

El estallido a finales de 2007 de la burbuja residencial en España y la subsiguiente crisis económica provocaron un cambio de paradigma en las políticas de vivienda. Mientras que en los años de exuberancia el principal problema fue la creciente dificultad de accesibilidad económica de un segmento de la población que iba ensanchándose a medida que los precios subían, con la lle- 
gada de la recesión, ante el crecimiento exponencial del número de hogares que, tanto en Cataluña (Bosch, 2017; ODESC/PAH, 2016, 2018) como en el conjunto de España (Amnistía Internacional España, 2015; Méndez y Plaza, 2016; Méndez, 2017; Sala, 2018), no podían atender sus gastos residenciales, la atención de la denominada emergencia habitacional pasó a ser la primera prioridad.

Durante los primeros años de la crisis, las medidas más relevantes impulsadas por el Gobierno central para dar respuesta a esta emergencia habitacional se circunscribieron a la protección del deudor hipotecario mediante disposiciones para facilitar la dación en pago, moderar el crecimiento de la deuda hipotecaria mediante el establecimiento de tipos de interés especiales, la posibilidad de renegociar o suprimir parte de la deuda, y la introducción de moratorias para la ejecución hipotecaria en caso de impago (véase, entre otros, el Real Decreto Ley 27/2012, de 15 de noviembre, de medidas urgentes para reforzar la protección a los deudores hipotecarios; la Ley 1/2013, de 14 de mayo, de medidas para reforzar la protección de los deudores hipotecarios, reestructuración de deuda y alquiler social; y el Real Decreto Ley 1/2015, de 27 de febrero, de mecanismo de segunda oportunidad, reducción de carga financiera y otras medidas de orden social).

Por su parte, el tipo de instrumentos de política de vivienda adoptados por la Generalitat de Cataluña fueron fundamentalmente ayudas directas a las personas, por lo general, en forma de prestaciones económicas, como las dirigidas al pago del alquiler o las prestaciones de especial urgencia con el objetivo de evitar lanzamientos en alquiler o ejecuciones hipotecarias por impago. Además, de forma complementaria, también se crearon otros mecanismos de ayuda en forma de asesoramiento y mediación con la puesta en marcha en 2010 de Ofideute, una red de oficinas de atención a familias sobreendeudadas que, bajo la coordinación de la Agencia de la Vivienda de Cataluña (AVC), intermedia entre las familias y las entidades financieras para arbitrar soluciones y así evitar la pérdida de la vivienda.

No obstante, en 2015 se produjo un cambio substancial en el modo de abordar la crisis residencial. Más allá de las ayudas directas antes mencionadas, el nuevo marco jurídico aprobado ese mismo año por el Gobierno catalán articuló un sistema orientado, por un lado, a reforzar la función social de la propiedad residencial y, por otro, a ampliar el parque de alquiler social. Los tres primeros textos legales responsables de este nuevo enfoque fueron: (i) el Decreto Ley $1 / 2015$, de 24 de marzo, de medidas extraordinarias y urgentes para la movilización de viviendas procedentes de procesos de ejecución hipotecaria; (ii) la Ley 14/2015, de 21 de julio, del impuesto sobre las viviendas vacías y de modificación de normas tributarias y de la Ley 3/2012; (iii) y la Ley 24/2015, de 29 de julio, de medidas urgentes para afrontar la emergencia en el ámbito de la vivienda y la pobreza energética. Esta última ley fue la culminación de la iniciativa legislativa popular impulsada en 2014 por la Plataforma de Afectados por la Hipoteca (PAH) con el apoyo del Observatorio de Derechos Económicos, Sociales y Culturales (ODESC) y la Alianza por la Pobreza Energética (APE). 
En los años siguientes, este marco legal fue desarrollándose no solo con nuevas normativas — como, por ejemplo, la Ley 4/2016, de 24 de diciembre, de medidas de protección del derecho a la vivienda de las personas en riesgo de exclusión residencial, o el Decreto Ley 17/2019, de 23 de diciembre, de medidas urgentes para mejorar el acceso a la vivienda, convalidado-, sino también con la intervención del Tribunal Constitucional (TC), puesto que algunas de las nuevas disposiciones fueron objeto de recurso de inconstitucionalidad.

En este contexto, el objetivo de este artículo es analizar los nuevos instrumentos de fomento de la vivienda de alquiler social que contempla la normativa catalana aprobada a partir de 2015 hasta inicios de 2020 desde seis variables que caracterizan el concepto de vivienda social en la actualidad: (i) el precio del alquiler; (ii) la forma de adjudicación; (iii) los requisitos de las personas destinatarias; (iv) la financiación pública del instrumento; (v) la titularidad del inmueble; (vi) y el tiempo durante el cual la vivienda será de alquiler social. Los nuevos mecanismos de fomento de la vivienda social objeto de esta investigación son los siguientes: (i) la adquisición de la propiedad de viviendas procedentes de procesos de ejecución hipotecaria mediante el tanteo y retracto; (ii) la cesión del uso de viviendas de entidades financieras y sociedades vinculadas; (iii) el alquiler social voluntario; (iv) el alquiler social obligatorio; (v) la expropiación de viviendas para incrementar el parque de alquiler social; (vi) y el programa de viviendas 60/40.

La principal aportación de este estudio radica en la ausencia de investigaciones similares sobre las nuevas formas de vivienda de alquiler social en España, de modo que este trabajo pretende llenar parte de este vacío y, de este modo, contribuir a mejorar la eficacia y eficiencia en todo el proceso de elaboración de las políticas de vivienda relacionadas.

El artículo se estructura del siguiente modo: tras este primer apartado introductorio, el segundo examina el concepto europeo de vivienda de alquiler social y construye, a partir de esta revisión, el marco teórico sobre el cual se desarrolla la investigación; el tercero analiza las nuevas formas de fomento de este tipo de vivienda en Cataluña; y, por último, el artículo concluye con una síntesis y discusión de los resultados.

\section{Marco teórico}

\subsection{La evolución del concepto de vivienda de alquiler social en Europa}

En Europa, el concepto de vivienda de alquiler social ha evolucionado a lo largo del tiempo, y se ha construido y reconstruido a medida que ha ido cambiando su rol político y social, así como su forma de provisión (Harloe, 1995). Desde hace tiempo existe un amplio consenso sobre la imposibilidad de establecer una definición única y cerrada al respecto en Europa (p. ej. United Nations, 2006: 10; Czischke y Pittini, 2007: 9-13; Heino et al., 2007: 18-21; Laino y Pittini, 2011: 22; Braga y Palvarini, 2013: 8-9; Caruso, 2013: 34-35). 
Según Harloe (1995: 13), la vivienda de alquiler social es aquella: (i) cuyo precio no está determinado por el beneficio; (ii) cuya propiedad recae sobre entidades sin ánimo de lucro o de lucro limitado en lo concerniente a la vivienda; (iii) cuya adjudicación se basa en el concepto de necesidad (a pesar de que no siempre vaya destinada a las personas con mayores niveles de necesidad); (iv) y que, dado que constituye un elemento central de la política de vivienda, está sometida a un intenso control público en aspectos como, por ejemplo, su número, calidad o condiciones de adjudicación. Esta definición refleja el modo en que la mayoría de los países del centro y el norte de Europa abordaron durante el desarrollo de sus estados de bienestar la escasez de vivienda tras la Segunda Guerra Mundial y los problemas de accesibilidad económica en el mercado residencial hasta finales de los años setenta. Durante este periodo, Francia, el Reino Unido, Austria u Holanda, entre otros, construyeron la mayor parte de sus grandes parques de alquiler social. De hecho, la política de vivienda en esos años pivotaba casi exclusivamente sobre la promoción de nueva vivienda pública de alquiler, por lo que en la literatura académica europea se usaban los términos vivienda social y vivienda de alquiler social como equivalentes.

Sin embargo, a partir de los años ochenta, los sistemas de vivienda del centro y el norte de Europa experimentaron profundas transformaciones: (i) se priorizaron las ayudas directas a los hogares en alquiler (ayudas a la demanda) en detrimento del fomento de la vivienda de alquiler social (ayudas a la oferta); (ii) empezó a promoverse el acceso a la propiedad, no solo mediante la privatización del parque social, sino también como forma de tenencia para los nuevos hogares y aquellos en alquiler privado, por lo que el concepto de vivienda social se abrió a otras formas de tenencia distintas del alquiler (se rompió la plena correspondencia con el de vivienda de alquiler social); (iii) y, en conjunto, se redujo el gasto público en política de vivienda, sobre todo, a causa de la caída de la promoción de nueva vivienda social (p. ej., Boelhouwer y Heijden, 1994; Priemus y Boelhouwer, 1998; Heijden, 2002: 329; Oxley, 2009). Ante esta reducción de la intervención pública, los sistemas residenciales estuvieron mucho más orientados hacia el mercado y, en coherencia, las definiciones de vivienda social formuladas en este nuevo contexto tendieron a ser menos exigentes que la anterior de Harloe en aspectos como la titularidad del inmueble o el control público del sector.

Merece especial atención la evolución del concepto de vivienda de alquiler social de CECODHAS-Housing Europe. Fundada en 1988, esta organización agrupa a unas 45 federaciones nacionales y regionales de promotores de vivienda social, pública y cooperativa de un total de 24 países europeos, las cuales gestionaban en 2019 en total más de 26 millones de viviendas, a saber, alrededor del 11\% del parque residencial de Europa. En 1998, CECODHAS propuso a la Comisión Europea que fuera considerada como aquella "...cuyo acceso se encuentra regulado por unas normas de adjudicación que favorecen aquellos hogares que tienen dificultades para encontrar un alojamiento en el mercado" (UNECE, 2003: 3; traducción del autor). De un modo similar, en 
2006 la definió como aquella «vivienda para aquellos hogares cuyas necesidades no son satisfechas por el mercado libre y que son adjudicadas mediante unas reglas» (Czischke, 2007: 7; traducción del autor). En 2011, pese a reconocer la existencia de aspectos clave como, por ejemplo, el modelo de financiación, los requisitos que deben cumplir las personas beneficiarias o la naturaleza de los actores implicados en la promoción y gestión, ante la diversidad de situaciones entre países comunitarios, CECODHAS estimó que solo había dos elementos nucleares comunes de la vivienda de alquiler social en la Unión Europea: la asequibilidad y la existencia de normas para su adjudicación mediante procedimientos administrativos (Laino y Pittini, 2011: 22).

Por su parte, la OECD también ha abordado el concepto de vivienda social. En 2011, la definieron en un sentido amplio como aquella «... de compraventa o alquiler a precios inferiores a los del mercado cuya adjudicación no sigue los mecanismos del mercado» (Andrews et al., 2011: 5; traducción del autor), sino determinados procedimientos administrativos (ibid., 2011: 43). Posteriormente, en 2015 delimitaron el concepto de vivienda de alquiler social a un «alojamiento residencial en alquiler a precios inferiores a los del mercado y adjudicado mediante criterios de elegibilidad» (OECD, 2015: 128; traducción del autor).

Una de las definiciones más exigentes de la última década que, de algún modo, recupera el enfoque de la vivienda de alquiler social de Harloe es la formulada por la Federación Europea de Organizaciones Nacionales de Trabajo con Personas sin Hogar (FEANTSA), entidad que aglutina a más de 130 organizaciones tanto de ámbito nacional como regional de 30 países europeos que trabajan con el objetivo de erradicar el problema de las personas sin hogar y sin techo. Según FEANTSA, es aquella que: (i) trata de corregir los fallos del mercado residencial; (ii) se dirige a aquellos grupos de población que no pueden satisfacer sus necesidades residenciales correctamente en el mercado privado de vivienda; (iii) tiene unas reglas de adjudicación claras (que pueden incluir requisitos como límites de ingresos, tiempo de residencia o nacionalidad, etcétera); (iv) disfruta de unos estándares adecuados que son regularmente controlados; (v) cuenta con subsidios públicos (en los que no se incluyen los beneficios fiscales ni las ayudas directas a los inquilinos para el pago de su vivienda); (vi) se proporciona, por lo general, sin fines de lucro; (vii) y está supervisada por las autoridades públicas (Pleace et al., 2011: 16; Baptista et al., 2015: 47).

En el ámbito nacional, no todos los países comunitarios disponen de una definición oficial sobre qué debe ser considerado como vivienda de alquiler social, ni tampoco las existentes suelen ser coincidentes. Esta diversidad entre países europeos se pone de relieve en los resultados del último cuestionario de la Organización para la Cooperación y el Desarrollo Económicos sobre este tema, en particular, en los diferentes términos, definiciones y características de los programas de viviendas de alquiler social (OECD, 2019). Pese a ello, tras examinar las definiciones vigentes, Braga y Palvarini (2013: 9) llegaron a la conclusión de que existían tres elementos comunes en las diferentes definiciones de los países comunitarios: (i) era un servicio de interés general; (ii) su principal objetivo era contribuir a incrementar la oferta de vivienda asequible; (iii) y se 
dirigía a determinados grupos socioeconómicos o en situación de vulnerabilidad. Braga y Palvarini (2013: 10-13) también identificaron cuatro aspectos que diferencian los diferentes modelos europeos: (i) el régimen de tenencia (alquiler, propiedad compartida o plena propiedad); (ii) los actores encargados de su provisión (gobiernos, empresas públicas, entidades sin ánimo de lucro o con lucro limitado, o empresas privadas); (iii) las personas beneficiarias seleccionadas por criterios objetivos de elegibilidad, por lo general, en función de un determinado umbral de ingresos; (iv) y los mecanismos de financiación (financiación pública, mercados financieros, crédito hipotecario, etcétera).

Granath-Hansson y Lundgren (2019), tras revisar los artículos publicados sobre vivienda social entre los años 2010 y 2017, llegaron a la conclusión de que existían cinco aspectos clave: (i) el grupo destinatario, en general, con recursos económicos limitados, por lo que su asignación se realiza a través de unas normas de adjudicación que garantizan el cumplimiento de este requisito; (ii) el régimen de tenencia; (iii) el tipo de proveedor (o titular del inmueble); (iv) los subsidios disponibles para que sea asequible (ya sean públicos o contribuciones financieras privadas); (v) y el modo de intervención pública (mediante regulación, promoción directa, subsidios, etcétera) mediante el cual se garantiza que su renta es inferior a la del mercado.

Refiriéndose únicamente al contexto de Inglaterra, Mattinson et al. (2019: 19) la definieron a partir de cuatro características básicas: (i) la asequibilidad de su renta para las familias destinatarias con bajos ingresos; (ii) su adjudicación mediante criterios determinados en función de los grupos necesitados; (iii) la titularidad y gestión de las mismas por parte de ayuntamientos y entidades sin ánimo de lucro debidamente registradas; (iv) y la regulación financiera a la que están sujetas las entidades gestoras de los mismos.

En los últimos años se observa en muchos países europeos una tendencia creciente a la generación de vivienda asequible que conceptualmente presenta problemas de encaje con algunas de las definiciones anteriores. Se trata de fórmulas híbridas dirigidas a promover vivienda a precios inferiores a los del mercado mediante la participación conjunta del Estado, el tercer sector, el mercado y actores comunitarios. Por ejemplo, en Francia, desde principios de 2000, se ha fomentado la vivienda privada de alquiler a precios intermedios entre el mercado y la vivienda de alquiler social tradicional, con medidas como incentivos fiscales, préstamos a bajo interés y subsidios para su reforma (Hoekstra, 2013). En Italia, en 2008 se creó el Sistema Integral de Fondos (Sistema Integrato dei Fondi, SIF) para impulsar la promoción de vivienda de alquiler a precios inferiores al mercado a través de partenariados entre actores públicos, privados, comunitarios y entidades sin ánimo de lucro (Ferri et al., 2019). En Austria, el ayuntamiento de la capital lanzó en 2011 la denominada Iniciativa Residencial de Viena (Wohnbauinitiative), consistente en créditos a bajo interés y la disponibilidad de terrenos con el fin de promover la construcción de vivienda de alquiler asequible para hogares con ingresos medios por parte de empresas mixtas conformadas por el gobierno local e inversores inmobiliarios con y sin ánimo de lucro (Mundt y Amann, 2018). 
En su estudio sobre este tipo de soluciones innovadoras publicoprivadas en la provisión de vivienda asequible en Austria, Inglaterra e Italia, Bortel y Gruis (2019) delimitaron cuatro dimensiones de análisis: (i) el grado de asequibilidad y el grupo destinatario; (ii) la gobernanza, en la cual se incluye la forma de adjudicación de las viviendas, la duración de los contratos de alquiler y su gestión; (iii) los mecanismos de financiación de las actuaciones; (iv) y el tipo de solución híbrida, a saber, el tipo de colaboración publicoprivada. En su opinión, estas nuevas fórmulas forman parte de la tendencia neoliberal de las políticas de vivienda, puesto que están directamente asociadas con la reducción del Estado en la promoción y la financiación directa de vivienda de alquiler social, lo que deriva en: (i) un mayor protagonismo de los actores privados y del tercer sector en su provisión; (ii) una mayor dependencia de la financiación privada; (iii) y lo que podríamos denominar una menor función social de estas viviendas. Respecto a este último punto, es importante tener presente que, por ejemplo, su precio suele situarse en una posición intermedia entre el del mercado y la vivienda social tradicional, y en algunos casos, para que la operación sea económicamente viable, la regulación del precio es solamente obligatoria durante un determinado periodo de tiempo, tras el cual la vivienda puede incorporarse en el mercado libre. Por todo ello, Bortel y Gruis (2019: 11) afirman:

...existen riesgos, particularmente para la salvaguarda de los valores de la vivienda pública, como la calidad, la asequibilidad y su asignación a grupos objetivo específicos. Aunque los acuerdos de gobernanza mitigan los riesgos a corto plazo, parece difícil asegurar la disponibilidad y la asequibilidad de la vivienda, así como mantener una participación activa y creciente de los actores de la comunidad, los inquilinos y los actores del mercado a largo plazo. (Bortel y Gruis, 2019: 11; traducción del autor)

Un elemento común, explícito o no, de las diferentes definiciones de vivienda de alquiler social es la asequibilidad. Este concepto se refiere a la capacidad económica del hogar para satisfacer los costes residenciales y suele medirse de dos formas: (i) mediante el porcentaje que representan estos respecto al total de ingresos del hogar; (ii) o a partir de la disponibilidad de recursos económicos suficientes para otras necesidades básicas del hogar como la comida, el transporte, el ocio o la ropa tras el pago de la vivienda (Milligan y Gilmour, 2012).

\subsection{Hacia un modelo de análisis de la vivienda social en la actualidad}

Desde una perspectiva histórica y territorial comparada entre países europeos, el concepto de vivienda de alquiler social es flexible y variable, y ha ido adaptándose a la realidad de cada momento y lugar, muy en particular, al modo y alcance de la intervención pública en su fomento. Actualmente no existe en Europa ni en el plano académico ni en el político-práctico una definición unívoca y cerrada al respecto. No obstante, de acuerdo con el apartado anterior, la literatura sobre esta cuestión tiende a centrar el examen de la vivienda de alquiler social desde cinco variables: (i) su precio (o asequibilidad) con relación 
Tabla 1. Aspectos que caracterizan la vivienda de alquiler social en Europa según diferentes autores y organizaciones, 1995-2019

\begin{tabular}{lccccc}
\hline \multicolumn{1}{c}{ Autor } & $\begin{array}{c}\text { Precio del } \\
\text { alquiler }\end{array}$ & $\begin{array}{c}\text { Forma de } \\
\text { adjudicación }\end{array}$ & $\begin{array}{c}\text { Requisitos } \\
\text { destinatarios }\end{array}$ & $\begin{array}{c}\text { Financiación } \\
\text { pública }\end{array}$ & $\begin{array}{c}\text { Titular del } \\
\text { inmueble }\end{array}$ \\
\hline Harloe (1995) & $\bullet$ & $\bullet$ & $\bullet$ & & $\bullet$ \\
CECODHAS 1998 (UNECE, 2003) & & $\bullet$ & $\bullet$ & \\
CECODHAS 2006 (Czischke, 2007) & & $\bullet$ & $\bullet$ & \\
Laino y Pittini (2011) & $\bullet$ & $\bullet$ & & \\
Andrews et al. (2011) & $\bullet$ & $\bullet$ & & \\
OECD (2015) & $\bullet$ & $\bullet$ & $\bullet$ & & \\
FEANTSA (Pleace et al., 2011; Baptista et al., 2015) & $\bullet$ & $\bullet$ & $\bullet$ & $\bullet$ & $\bullet$ \\
Braga y Palvarini (2013) & $\bullet$ & $\bullet$ & $\bullet$ & $\bullet$ & $\bullet$ \\
Granath-Hansson y Lundgren (2019) & $\bullet$ & $\bullet$ & $\bullet$ & $\bullet$ & $\bullet$ \\
Mattinson et al. (2019) & $\bullet$ & $\bullet$ & $\bullet$ & & $\bullet$ \\
Bortel y Gruis (2019) & $\bullet$ & $\bullet$ & $\bullet$ & $\bullet$ & $\bullet$ \\
\hline
\end{tabular}

Fuente: elaboración propia.

al mercado y a la capacidad de los hogares; (ii) el grupo destinatario; (iii) la forma de adjudicación de la vivienda; (iv) la titularidad del inmueble; (v) y el modo de financiación de la provisión de esta vivienda social (tabla 1).

Esta investigación analiza las nuevas formas de fomento de la vivienda de alquiler social que ha introducido la normativa catalana durante el periodo 2015-2020 desde estas cinco variables, a las cuales se añade una sexta: el tiempo durante el cual puede asegurarse que la vivienda se destinará al alquiler social. El motivo de la inclusión de esta nueva variable responde, como apuntan Bortel y Gruis (2019), al hecho de que las nuevas fórmulas de promoción suelen garantizar su función social solo durante un periodo de tiempo determinado. Obviamente, este factor está estrechamente ligado a la titularidad del inmueble y al nivel de financiación pública necesario, mientras que las tres variables restantes (precio, adjudicación y destinatarios) nos permiten evaluar la función social que desempeña cada tipo de vivienda en el sistema residencial. Por ello, el análisis mediante estas seis variables nos permitirá un mayor conocimiento de las ventajas y limitaciones de cada uno de los instrumentos de fomento estudiados en Cataluña, lo cual, por extensión, esperemos que contribuya a mejorar su diseño, programación, articulación e implementación.

\section{Las nuevas formas de fomento del alquiler social en Cataluña}

\subsection{Aspectos generales de la vivienda de alquiler social en Cataluña}

La vivienda de alquiler social ha sido un instrumento residual en la política de vivienda española y catalana: ni siquiera representa el 1,5\% del total de viviendas principales, un porcentaje muy inferior a la práctica totalidad de países comunitarios. Solamente Grecia, Chipre, Letonia y Luxemburgo disponen de un parque más exiguo (gráfico 1). 
Gráfico 1. Porcentaje de vivienda de alquiler social sobre el total del parque. Unión Europea (UE-28) y países miembros, 2017-2019

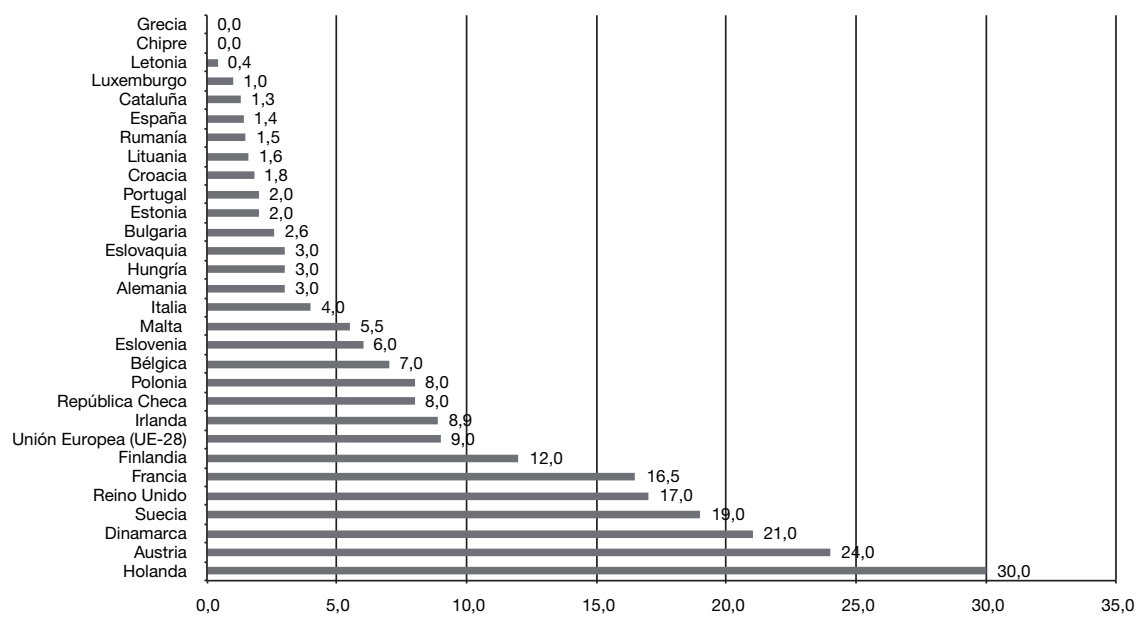

Fuente: Cataluña, según datos de la memoria del Plan Territorial Sectorial de Vivienda de Cataluña aprobado inicialmente mediante Resolución de 7 de marzo de 2019; España, según datos de la Encuesta EINSFOESSA de 2018; resto de países, según datos de Pittini et al. (2019), excepto Croacia, Malta, Hungría, Lituania, Rumanía y Letonia, según datos de Pittini et al. (2017).

Asimismo, en el plano legal, no existe una definición oficial de vivienda de alquiler social ni para toda España ni en Cataluña. No obstante, el artículo 4 de las normas del Plan Territorial Sectorial de Vivienda de Cataluña, aprobado inicialmente en marzo de 2019, la define como «... aquella cuya renta es inferior a la del mercado a causa de la intervención directa o indirecta de la Administración mediante algunos de los instrumentos de política de vivienda establecidos en la Ley 18/2007, de 28 de diciembre, del derecho a la vivienda, o en otras disposiciones aprobadas con esta finalidad» (Departament de Territori i Sostenibilitat, 2019a: 7; traducción del autor). Tomando esta definición, desde 2015 hasta inicios de 2020 se aprobaron en Cataluña diferentes iniciativas legislativas para ampliar la oferta de vivienda de alquiler social. En concreto, nos referimos a los siguientes seis instrumentos objeto de la presente investigación: (i) la adquisición de la propiedad de viviendas procedentes de procesos de ejecución hipotecaria mediante el tanteo y retracto; (ii) la cesión del uso de viviendas de entidades financieras y sociedades vinculadas; (iii) el alquiler social voluntario; (iv) el alquiler social obligatorio; (v) la expropiación de viviendas para incrementar el parque de alquiler social; (vi) y el programa de viviendas 60/40.

\subsection{La adquisición de la propiedad de viviendas procedentes de procesos de ejecución hipotecaria mediante el tanteo y retracto}

Con el propósito de intervenir en el mercado ante la venta de paquetes de viviendas de entidades financieras y sociedades vinculadas a fondos de inver- 
sión internacionales, y poder movilizar parte de ellas hacia el alquiler social, el Decreto Ley 1/2015 introdujo el derecho de tanteo y retracto a favor de la Generalitat (directamente o a través de promotores sociales, entidades de derecho público o sin ánimo de lucro) de la primera y posteriores transmisiones de viviendas adquiridas en un proceso de ejecución hipotecaria o mediante compensación o pago de deuda con garantía hipotecaria después de la entrada en vigor de la Ley 18/2007, de 28 de diciembre, del derecho a la vivienda. Gracias a esta medida, a finales de 2018, el parque público que administraba la Agencia de la Vivienda de Cataluña (AVC) se había incrementado en 1.256 unidades (Agència de l'Habitatge de Catalunya, 2019: 35).

Lógicamente, el coste de la aplicación de este instrumento recae fundamentalmente sobre los presupuestos públicos. La AVC destinó 30,7 millones de euros en 2017 y 52,7 millones en el siguiente año para la adquisición y reforma de 848 viviendas (Agència de l'Habitatge de Catalunya, 2019: 31). Y para impulsar la adquisición de viviendas mediante este instrumento (y también por vía de la compraventa), el Instituto Catalán de Finanzas (ICF) creó en 2018 una línea de financiación dirigida a ayuntamientos y entidades sin ánimo de lucro con las siguientes condiciones financieras: (i) importe a partir de 25.000 euros hasta un máximo de 10 millones y 90.000 euros por vivienda, llegando a cubrir el total del coste de la compra y la rehabilitación si fuera necesario; (ii) un plazo máximo de 25 años con posibilidad de carencia de dos años; (iii) y un interés fijo del 3,25\%. Además, los créditos concedidos cuentan con una bonificación del tipo de interés del $2 \%$ por parte de la AVC, y los ayuntamientos y entidades deudoras adheridas a esta línea de préstamos bonificados disponen de subvenciones (en régimen de concurrencia pública no competitiva) para cubrir la diferencia entre la renta que efectivamente abonan los residentes en función de sus ingresos ponderados (con un importe mínimo de 30 euros mensuales, gastos de comunidad incluidos) y la denominada contraprestación objetiva equivalente a la cuota de amortización del préstamo (capital e intereses) de esa vivienda (véase, por ejemplo, la Resolución TES/1957/2018, de 7 de agosto, DOGC núm. 7686, de 16 de agosto de 2018). Es importante señalar que las viviendas adquiridas mediante esta línea de financiación deben: (i) calificarse como de protección oficial por un periodo equivalente a la vigencia del préstamo; (ii) destinarse a alquiler social durante todo el tiempo en que se mantenga el régimen de propiedad temporal (regulado en el artículo 547 del Código Civil de Cataluña), el cual se constituye por un plazo máximo de 75 años (una vez pasado, la AVC adquirirá su propiedad sucesiva); (iii) y destinarse a unidades familiares con ingresos no superiores a 3,5 veces el indicador de renta de suficiencia (IRSC) (desde 2017 hasta principios de 2020 este indicador era de 569,12 euros mensuales) (véase el conjunto de detalles técnicos en la tabla 3).

Por último, conviene tener presente que este instrumento se concibió con carácter temporal, inicialmente para un periodo de seis años a partir de su entrada en vigor, pero el Decreto Ley 17/2019 amplió dicho plazo hasta los 12 años. 


\subsection{La cesión del uso de viviendas de entidades financieras y sociedades vinculadas}

Otro mecanismo de fomento del alquiler social que ha ido consolidándose en los últimos años es la cesión voluntaria de viviendas por parte de entidades financieras y sociedades vinculadas mediante convenio entre estas y la AVC. En 2014, el parque privado propiedad de entidades financieras administrado por la AVC era de tan solo 161 unidades, de 376 en 2015, pero en los años siguientes creció de forma notable hasta alcanzar las 2.837 viviendas a finales de 2018 (Agència de l'Habitatge de Catalunya, 2016: 47; 2019: 31). Los factores de este incremento, muy probablemente, cabe buscarlos en tres normas aprobadas en 2015: (i) el Decreto Ley 1/2015; (ii) la Ley 14/2015; (iii) y la Ley 24/2015.

El primer texto legal, además de la medida del tanteo y retracto antes expuesta, para movilizar el parque desocupado: (i) estableció el deber de que las viviendas adquiridas en un proceso de ejecución hipotecaria o en compensación o pago de deuda con garantía hipotecaria cumplieran con los requisitos de habitabilidad exigibles a las viviendas; (ii) creó el registro de viviendas vacías y ocupadas sin título habilitante en el cual obligatoriamente debían inscribirse dichas viviendas; (iii) y facultó a la Administración, por un lado, para ordenar la ejecución de las obras necesarias para alcanzar las condiciones de habitabilidad y, por otro, también para poder acordar la expropiación temporal del usufructo de esta vivienda por un plazo mínimo de cuatro años y máximo de 10 en caso de que fuera necesaria la ejecución forzosa subsidiaria. Y con el fin de impulsar su cesión, determinó que no era procedente acordar la ejecución forzosa cuando, entre otros supuestos, la propiedad cediera el usufructo de la vivienda a la Administración para que esta ejecutara dichos trabajos y pudiera disponer de ella durante un periodo de tiempo determinado (artículo 4 del Decreto Ley 1/2015).

El segundo texto creó el impuesto sobre viviendas vacías como un tributo propio de la Generalitat de Cataluña para gravar el incumplimiento de su función social por el hecho de permanecer desocupadas durante más de dos años sin causa justificada. Los sujetos pasivos de este impuesto son las personas jurídicas propietarias o titulares de un derecho de usufructo, de superficie o de cualquier otro derecho real que permita la explotación económica del inmueble. Para fomentar la cesión de dichas viviendas, la ley previó dos medidas adicionales: (i) exención del impuesto para aquellas viviendas puestas a disposición de programas de alquiler social de forma acordada con la Administración; (ii) y diferentes niveles de bonificaciones en la cuota para aquellos sujetos pasivos en función del porcentaje de su parque de vivienda destinado a alquiler asequible, directamente o por medio de la Administración o entidades del tercer sector.

El tercero, la Ley 24/2015, en su artículo 7, estableció la posibilidad de que la Administración pudiera resolver la cesión obligatoria de viviendas vacías propiedad de personas jurídicas no exentas del pago del impuesto sobre viviendas vacías siempre que en el municipio donde se ubicaran hubiera unidades familiares en situación de riesgo de exclusión residencial (según definición formu- 
lada por la misma ley, que tiene en consideración los ingresos y la composición de la unidad familiar) (véase el conjunto de detalles técnicos en la tabla 3). Este artículo fue suspendido en junio de 2016 por el recurso de inconstitucionalidad interpuesto por el Gobierno central, pero el TC, en su sentencia 13/2019, de 31 de enero de 2019, desestimó la impugnación de este artículo, por lo que recuperó su vigencia en febrero de 2019. Actualmente, el instrumento de la cesión obligatoria sigue vigente, aunque con algún cambio derivado del Decreto Ley 17/2019, como, por ejemplo, la exigencia, como requisito previo, del incumplimiento por parte de la propiedad del requerimiento de la obligación de que la vivienda esté ocupada legalmente. Uno de los elementos más relevantes que ha introducido al respecto el Decreto Ley 17/2019 es la regulación de las condiciones económicas de la cesión obligatoria de viviendas. En ausencia de acuerdo entre las partes, la compensación estipulada es del $40 \%$ de la renta máxima que correspondería a una vivienda de protección oficial de régimen especial hasta que se actualicen los precios de acuerdo con el artículo 83.bis de la Ley 18/2007.

Para mayor seguridad jurídica, la Ley 4/2016 incluyó una disposición específica que explicitaba la capacidad de la Generalitat y del resto de administraciones públicas catalanas para suscribir convenios de colaboración con las personas jurídicas titulares de viviendas inscritas en el registro de viviendas vacías y viviendas ocupadas sin título habilitante con el objetivo de aumentar el parque social de viviendas asequibles de alquiler (disposición adicional tercera). En ausencia de un convenio tipo obligatorio, en la práctica cada uno de los que se han suscrito han establecido las condiciones particulares que se han considerado más oportunas en cada momento. Sin embargo, como puede observarse en la tabla 2 , los cuatro convenios analizados comparten muchos aspectos: (i) la existencia de una contraprestación que la AVC debe satisfacer a la propiedad; (ii) la renta mensual, por lo general, se sitúa alrededor de los 150 euros mensuales y no debe superar el 30\% de los ingresos de la unidad familiar; (iii) el porcentaje de viviendas ocupadas irregularmente se limita a un máximo del 50\% del total; (iv) la duración del convenio oscila entre los cuatro y los ocho años; (v) el tiempo de cesión de las viviendas varía entre los cinco y los ocho años; (vi) y las obras que puede asumir la propiedad para cumplir habitabilidad tienen un umbral de coste de entre 3.000 y 4.000 euros por vivienda.

Respecto a la selección de los inquilinos, el procedimiento establecido por la AVC (Agència de l'Habitatge de Catalunya, 2017: 6-7) y así recogido en los mencionados convenios prioriza la atención de las necesidades de la Mesa de Emergencias y, solo en el caso que estas viviendas sean desestimadas por dicha mesa, se prevé su ofrecimiento: (i) en primer lugar, a los servicios sociales del municipio; (ii), en segundo lugar, a las personas inscritas en el Registro de Solicitantes de VPO; (iii) y, por último, a la Mesa del Tercer Sector Social de Cataluña. En este sentido, hay que tener presente que, en un porcentaje elevado (limitado a un máximo del 50\% de las viviendas cedidas), las personas adjudicatarias serán las ocupantes de la vivienda, por ejemplo, antiguos deudores hipotecarios que, tras un procedimiento de ejecución hipotecaria, se encuentran en 
Tabla 2. Principales aspectos de los convenios de colaboración entre la Agencia de Vivienda de Cataluña y determinadas entidades financieras para la cesión de viviendas destinadas a alquiler social. Cataluña, 2016-2018

\begin{tabular}{|c|c|c|c|c|c|c|c|}
\hline $\begin{array}{l}\text { Convenios de } \\
\text { cesión del uso } \\
\text { de viviendas }\end{array}$ & $\begin{array}{l}\text { Contraprestación } \\
\text { mensual de AVC } \\
\text { a la propiedad }\end{array}$ & $\begin{array}{l}\text { Renta mensual } \\
\text { de alquiler }\end{array}$ & $\begin{array}{l}\text { Selección } \\
\text { inquilinos }\end{array}$ & $\begin{array}{l}\text { Tipo de } \\
\text { viviendas }\end{array}$ & $\begin{array}{l}\text { Duración } \\
\text { convenio }\end{array}$ & $\begin{array}{l}\text { Duración } \\
\text { cesión } \\
\text { viviendas }\end{array}$ & $\begin{array}{l}\text { Obras que } \\
\text { asume la } \\
\text { propiedad } \\
\text { para cumplir } \\
\text { habitabilidad }\end{array}$ \\
\hline $\begin{array}{l}\text { Convenio } \\
\text { AVC y Bankia } \\
(10.5 .2018)\end{array}$ & $\begin{array}{l}75 \text { euros por } \\
\text { vivienda ocupada } \\
125 \text { euros por } \\
\text { vivienda vacía }\end{array}$ & $\begin{array}{l}150 \text { euros } \\
\text { (media), sin } \\
\text { superar } 30 \% \\
\text { ingresos netos } \\
\text { del hogar }\end{array}$ & $\begin{array}{l}\text { Prioridad } \\
\text { Mesa de } \\
\text { Emergencias }\end{array}$ & $\begin{array}{l}\text { Mínimo 50\% } \\
\text { viviendas } \\
\text { vacías }\end{array}$ & $\begin{array}{l}4 \text { años } \\
\text { (prorrogable } \\
\text { por } 4 \text { años } \\
\text { más) }\end{array}$ & 6 años & $\begin{array}{l}\text { Hasta } 3.000 \\
\text { euros por } \\
\text { vivienda }\end{array}$ \\
\hline $\begin{array}{l}\text { Convenio } \\
\text { AVC y Abanca } \\
(3.7 .2017)\end{array}$ & $\begin{array}{l}150 \text { euros por } \\
\text { vivienda }\end{array}$ & $\begin{array}{l}150 \text { euros } \\
\text { (media), sin } \\
\text { superar } 30 \% \\
\text { ingresos netos } \\
\text { del hogar }\end{array}$ & $\begin{array}{l}\text { Prioridad } \\
\text { Mesa de } \\
\text { Emergencias }\end{array}$ & $\begin{array}{l}\text { Mínimo 50\% } \\
\text { viviendas } \\
\text { vacías }\end{array}$ & $\begin{array}{l}4 \text { años (pro- } \\
\text { rrogable por } 4 \\
\text { años más) }\end{array}$ & 5 años & $\begin{array}{l}\text { Hasta } 4.000 \\
\text { euros por } \\
\text { vivienda }\end{array}$ \\
\hline $\begin{array}{l}\text { Convenio AVC } \\
\text { y Criteria Caixa } \\
(23.1 .2017)\end{array}$ & $\begin{array}{l}75 \text { euros por vivi- } \\
\text { enda ocupada } \\
125 \text { euros por vivi- } \\
\text { enda vacía }\end{array}$ & $\begin{array}{l}150 \text { euros } \\
\text { (media), sin } \\
\text { superar } 30 \% \\
\text { ingresos netos } \\
\text { del hogar }\end{array}$ & $\begin{array}{l}\text { Prioridad } \\
\text { Mesa de } \\
\text { Emergencias }\end{array}$ & $\begin{array}{l}\text { Mínimo 50\% } \\
\text { viviendas } \\
\text { vacías }\end{array}$ & $\begin{array}{l}4 \text { años (pror- } \\
\text { rogable anual- } \\
\text { mente) }\end{array}$ & 6 años & $\begin{array}{l}\text { Hasta } 3.000 \\
\text { euros por } \\
\text { vivienda }\end{array}$ \\
\hline $\begin{array}{l}\text { Convenio AVC } \\
\text { y Caixabank- } \\
\text { Buildingcenter } \\
(18.2 .2016)\end{array}$ & $\begin{array}{l}75 \text { euros por } \\
\text { vivienda ocupada } \\
125 \text { euros por } \\
\text { vivienda vacía }\end{array}$ & $\begin{array}{l}\text { Entre } 150 \text { y } 350 \\
\text { euros, sin } \\
\text { superar } 30 \% \\
\text { ingresos netos } \\
\text { del hogar }\end{array}$ & $\begin{array}{l}\text { Prioridad } \\
\text { Mesa de } \\
\text { Emergencias } \\
\text { (criterios AVC) }\end{array}$ & $\begin{array}{l}\text { Mínimo 50\% } \\
\text { viviendas } \\
\text { vacías }\end{array}$ & $\begin{array}{l}8 \text { años (pror- } \\
\text { rogable por un } \\
\text { año más) }\end{array}$ & 8 años & $\begin{array}{l}\text { Hasta } 3.000 \\
\text { euros por } \\
\text { vivienda }\end{array}$ \\
\hline
\end{tabular}

Fuente: elaboración propia a partir de los convenios suscritos [en línea] <http://agenciahabitatge.gencat.cat/convenis> [consulta: 24 de abril de 2020].

situación previa al lanzamiento, situaciones irregulares derivadas de un contrato de alquiler resuelto por impago u ocupaciones sin título o en precario.

\subsection{El alquiler social voluntario}

La bonificación del impuesto sobre viviendas vacías prevista en la Ley 24/2015 no implica obligatoriamente que las viviendas de alquiler social o asequible sean cedidas a la Administración, pues pueden ser gestionadas directamente por la propiedad o por terceros. Es lo que podría denominarse alquiler social voluntario incentivado fiscalmente. En estos casos, la AVC valida estas viviendas, para lo cual deben cumplir con los siguientes requisitos: (i) una renta mensual inferior en un 25\% a la del mercado, sin superar el límite de los 225, 300 o 400 euros mensuales según el municipio de acuerdo con la Orden GAH/16/2017, de 31 de enero; (ii) y que la parte arrendataria tenga unos ingresos inferiores a los máximos establecidos para acceder a una vivienda de protección oficial (véase el conjunto de detalles técnicos en la tabla 3). 


\subsection{El alquiler social obligatorio}

El denominado alquiler social obligatorio fue regulado por primera vez en la Ley 24/2015 y básicamente consiste en la obligatoriedad de que, en determinadas situaciones, la propiedad de la vivienda ofrezca una propuesta de alquiler social a las personas inquilinas o antiguos propietarios que, por motivos económicos, no pueden satisfacer la renta o la hipoteca y no disponen de una alternativa residencial. Para que la propuesta sea considerada adecuada: (i) la renta no debe superar entre el $10 \%$ y el $18 \%$ de los ingresos ponderados de la unidad familiar según el nivel de ingresos familiares; (ii) y preferiblemente debe ser la vivienda objeto del procedimiento, aunque alternativamente puede ser otra dentro del mismo término municipal o fuera de este si no afecta negativamente la situación de exclusión residencial de la unidad familiar.

A raíz de la interposición del recurso de inconstitucionalidad núm. 25012016, el alquiler social obligatorio de la Ley 24/2015 fue suspendido por el TC desde junio de 2016 hasta la publicación de la sentencia núm. 13/2019, de 31 de enero de 2019, la cual desestimó el recurso interpuesto sobre este instrumento. Ello llevó al legislador catalán a buscar mecanismos alternativos durante la suspensión mediante nuevas disposiciones legales. En concreto, la Ley 4/2016 también contemplaba un instrumento análogo pero bajo el concepto de obligación de realojo (artículo 16). Los supuestos eran prácticamente los mismos que los establecidos en la Ley 24/2015, pero, a diferencia del alquiler social obligatorio, el realojo obligatorio se planteó como un sistema transitorio y excepcional para un periodo de cinco años desde la entrada en vigor de la ley, con la posibilidad de prorrogarse por un periodo máximo de tres años en caso de persistir las condiciones de emergencia social (disposición final quinta). Es importante subrayar que esta medida también fue suspendida desde octubre de 2017 hasta febrero de 2019 por el TC tras la interposición del recurso de inconstitucionalidad núm. 4752-2017, y la posterior sentencia núm. 8/2019, de 17 de enero de 2019, confirmó de nuevo la legalidad de dicha medida.

Finalmente, el Decreto Ley 17/2019 modificó algunos aspectos del alquiler social obligatorio regulado en la Ley 24/2015. Entre otros: (i) la duración mínima de los contratos de alquiler social se amplió de tres a cinco años y, en caso de que el titular de la vivienda fuera una persona jurídica, a siete años; (ii) y la obligación de ofrecer una propuesta de alquiler social se hizo extensiva a cualquier reclamación de una deuda hipotecaria, a demandas de desahucio por vencimiento de la duración del título jurídico que habilite la ocupación, y a demandas por ausencia de título jurídico habilitante alguno cuando el demandante tenga la condición de gran tenedor, siempre que la vivienda se encuentre vacía antes de la ocupación y esta hubiera tenido lugar seis meses antes de la entrada en vigor del Decreto Ley 17/2019 (véase el conjunto de detalles técnicos en la tabla 3).

\subsection{La expropiación de viviendas}

La versión inicial de la Ley 18/2007 del derecho a la vivienda ya recogía en su artículo 42 la potestad de la expropiación temporal del usufructo de viviendas 
vacías en determinadas situaciones para destinarlas al alquiler social, pero ha sido en los últimos años cuando este instrumento ha experimentado un mayor desarrollo legislativo. En primer lugar, como veíamos anteriormente, el Decreto Ley $1 / 2015$ incorporó la posibilidad de acordar la expropiación temporal del usufructo de viviendas vinculada a la ejecución forzosa subsidiaria de obras para alcanzar las condiciones de habitabilidad. En el año siguiente, la Ley 4/2016 estableció la posibilidad de aplicar la expropiación forzosa del uso temporal de las viviendas inscritas en el registro de viviendas vacías y viviendas ocupadas sin título habilitante a causa del incumplimiento de su función social para que fueran incorporadas al parque de alquiler social (artículo 15). Sin embargo, esta medida fue suspendida por el TC desde finales de octubre de 2017 hasta finales de marzo de 2018 por la interposición del recurso de inconstitucionalidad núm. 4752-2017, pero la sentencia del TC ratificó que esta medida era conforme a derecho (sentencia núm. 8/2019, de 17 de enero).

La Ley 4/2016 también preveía la expropiación del uso de viviendas en el caso de transmisiones derivadas de acuerdos de compensación, dación en pago o créditos hipotecarios, por imposibilidad de retornar el crédito, si el transmitente, sin alternativa residencial, se encontraba en riesgo de exclusión residencial, y el adquirente estaba inscrito en el registro de viviendas vacías y viviendas ocupadas sin título habilitante (artículo 17). No obstante, esta disposición no solo fue suspendida también por el recurso de inconstitucionalidad anterior, sino declarada inconstitucional y nula en la posterior sentencia.

Más recientemente, el Decreto Ley 17/2019 dio un nuevo impulso a la institución expropiatoria para aumentar la oferta de alquiler social. Entre otros aspectos: (i) modificó la Ley 18/2007 incorporando la expropiación forzosa por incumplimiento de la función social de la propiedad de la vivienda; (ii) y amplió la facultad expropiatoria recogida en el artículo 15 de la Ley 4/2016 incluyendo, además del uso temporal, también su dominio (véase el conjunto de detalles técnicos en la tabla 3).

Pese a la ausencia de estadísticas oficiales, a causa de la suspensión realizada por el TC sobre parte de la Ley 4/2016, la posterior declaración de nulidad de algunos aspectos de dicha ley y el escaso tiempo transcurrido tras la entrada en vigor del Decreto Ley 17/2019, cabe esperar que actualmente el número de viviendas de alquiler social generadas mediante la potestad expropiatoria sea mínimo.

\subsection{El programa de viviendas $60 / 40$}

El artículo 5.6 de la Ley 24/2015 estableció el deber de las administraciones públicas de garantizar un realojo adecuado a las personas y unidades familiares en situación de riesgo de exclusión residencial y en proceso de desahucio de su vivienda habitual. El programa 60/40 se creó para poder dar cumplimiento a este mandato, en particular, para poder ofrecer una solución residencial a aquellas personas y unidades familiares que, pese a encontrarse en esta situación y disponer de una valoración favorable de la Mesa de Emergencias, veían 
desatendidas sus necesidades residenciales en una vivienda de alquiler o de cesión de uso, de gestión pública. Su funcionamiento se basa en la colaboración entre la Generalitat de Cataluña y la administración local correspondiente. Los ayuntamientos y consejos comarcales pueden alquilar viviendas en el mercado privado y pedir su adhesión a la Red de Viviendas de Inserción para cederlas en uso o subarriendo mediante contrato a una unidad familiar que reúna los requisitos anteriores. La AVC aporta el 60\% del coste anual del alquiler, sin superar los 3.000 euros anuales o los 4.500 según el tipo de municipio; la unidad familiar se hace cargo de una parte pagando un canon correspondiente al $10 \%, 12 \%$ o $18 \%$ de sus ingresos (según volumen de ingresos), y el importe restante es satisfecho por la administración local (véase el conjunto de detalles técnicos en la tabla 3).

Según datos de la Generalitat, en 2017 se adjudicaron a través de las mesas de emergencia las primeras 18 viviendas de este programa gestionadas por la AVC, y en 2018 fueron 54 (Departament de Territori i Sostenibilitat, 2019b).

Tabla 3. Síntesis de los aspectos técnicos de los diferentes instrumentos de fomento de la vivienda social introducidos en Cataluña en el periodo 2015-2020

\begin{tabular}{|c|c|c|c|c|c|c|}
\hline $\begin{array}{l}\text { Mecanismo de } \\
\text { fomento }\end{array}$ & $\begin{array}{l}\text { Precio alquiler, } \\
\text { canon o cesión } \\
\text { de uso }\end{array}$ & $\begin{array}{l}\text { Forma de } \\
\text { adjudicación }\end{array}$ & $\begin{array}{c}\text { Requisitos } \\
\text { destinatarios }\end{array}$ & $\begin{array}{l}\text { Financiación } \\
\text { pública/costes }\end{array}$ & $\begin{array}{l}\text { Titular del } \\
\text { inmueble }\end{array}$ & $\begin{array}{l}\text { Tiempo en que esa } \\
\text { vivienda será de } \\
\text { alquiler social }\end{array}$ \\
\hline $\begin{array}{l}\text { Tanteo y retracto } \\
\text { directamente } \\
\text { por parte de la } \\
\text { Generalitat de } \\
\text { Cataluña }\end{array}$ & $\begin{array}{l}10 \%, 12 \% \text { o } 18 \% \\
\text { de los ingresos } \\
\text { ponderados de la } \\
\text { unidad familiar } \\
\text { según estos sean } \\
\text { inferiores a } 0,89 \\
\text { IRSC, } 0,95 \text { IRSC } \\
\text { o superiores }\end{array}$ & $\begin{array}{l}\text { Prioritariamente } \\
\text { por la mesa de } \\
\text { valoración de situa- } \\
\text { ciones de emergen- } \\
\text { cias económicas y } \\
\text { sociales (Mesa de } \\
\text { Emergencias) }\end{array}$ & $\begin{array}{l}\text { Personas en } \\
\text { situación de emer- } \\
\text { gencia económica } \\
\text { y social } \\
\text { Ingresos máximos } \\
\text { ponderados entre } 2 \\
\text { y 3,5 IRSC }\end{array}$ & $\begin{array}{l}\text { Coste íntegro adqui- } \\
\text { sición y reforma (si } \\
\text { fuera preciso) }\end{array}$ & $\begin{array}{l}\text { Titularidad pública } \\
\text { (Generalitat de } \\
\text { Cataluña) }\end{array}$ & $\begin{array}{l}\text { Forma indefinida } \\
\text { (mientras la Adminis- } \\
\text { tración la destine a } \\
\text { vivienda social) }\end{array}$ \\
\hline \multirow{2}{*}{$\begin{array}{l}\text { Tanteo y retracto a } \\
\text { través de ayuntamien- } \\
\text { tos y entidades sin } \\
\text { ánimo de lucro con } \\
\text { financiación } \\
\text { ICF (durante amorti- } \\
\text { zación crédito, } \\
25 \text { años) }\end{array}$} & $\begin{array}{l}\text { Módulo vigente VPO } \\
\text { régimen general (sin } \\
\text { superar cuota amorti- } \\
\text { zación préstamo) }\end{array}$ & $\begin{array}{l}\text { Registro Solicitantes } \\
\text { de Viviendas de Pro- } \\
\text {-tección Oficial (VP0) } \\
\text { (Decreto 106/2009) }\end{array}$ & \multirow[t]{2}{*}{$\begin{array}{l}\text { Unidades familiares } \\
\text { con ingresos no } \\
\text { superiores a } 3,5 \\
\text { IRSC }\end{array}$} & $\begin{array}{l}\text { Coste íntegro adqui- } \\
\text { sición y reforma } \\
\text { (si fuera preciso) } \\
\text { hasta } 90 \text { mil euros }\end{array}$ & \multirow{3}{*}{$\begin{array}{l}\text { Titularidad pública } \\
\text { (ayuntamiento) } 0 \\
\text { privada (sin ánimo } \\
\text { de lucro) mientras se } \\
\text { mantenga el régimen } \\
\text { de propiedad tempo- } \\
\text { ral (máximo } 75 \text { años), } \\
\text { y luego traspaso } \\
\text { propiedad a AVC }\end{array}$} & \multirow{3}{*}{$\begin{array}{l}\text { Forma indefinida } \\
\text { (mientras la Adminis- } \\
\text { tración la destine a } \\
\text { vivienda social) } \\
\end{array}$} \\
\hline & $\begin{array}{l}\text { Unidades familiares } \\
\text { con ingresos no } \\
\text { superiores a } 1,86 \\
\text { IRSC: en función de } \\
\text { sus ingresos (mínimo } \\
30 \text { euros) }\end{array}$ & $\begin{array}{l}\text { Mesa Emergencias } \\
\text { (15\% viviendas } \\
\text { reservadas en caso } \\
\text { de más de } 7 \text { vivien- } \\
\text { das adquiridas) }\end{array}$ & & $\begin{array}{l}\text { por vivienda } \\
\text { Bonificación } \\
\text { intereses (AVC) } \\
\text { Subvenciones (AVC) }\end{array}$ & & \\
\hline $\begin{array}{l}\text { Tanteo y retracto } \\
\text { a través de ayunta- } \\
\text { mientos y entidades } \\
\text { sin ánimo de lucro } \\
\text { con financiación ICF } \\
\text { (después amortiza- } \\
\text { ción crédito) }\end{array}$ & $\begin{array}{l}\text { El valor menor de } \\
\text { los dos siguientes: } \\
\text { módulo VP0 vigente, } \\
\text { o renta } 25 \% \text { inferior } \\
\text { al alquiler medio } \\
\text { del mercado del } \\
\text { municipio }\end{array}$ & $\begin{array}{l}\text { Carácter general, } \\
\text { Registro Solicitan- } \\
\text { tes VPO (Decreto } \\
\text { 106/2009) } \\
\text { Carácter excepcional, } \\
\text { por la Mesa de } \\
\text { Emergencias }\end{array}$ & $\begin{array}{l}\text { Según normativa } \\
\text { vigente en su } \\
\text { momento (actual- } \\
\text { mente unidades } \\
\text { familiares con ingre- } \\
\text { sos no superiores a } \\
5 \text { IRSC en municipios } \\
\text { de demanda fuerte y } \\
\text { acreditada) }\end{array}$ & & & \\
\hline
\end{tabular}


Tabla 3. Síntesis de los aspectos técnicos de los diferentes instrumentos de fomento de la vivienda social introducidos en Cataluña en el periodo 2015-2020 (continuación)

\begin{tabular}{|c|c|c|c|c|c|c|}
\hline $\begin{array}{l}\text { Mecanismo de } \\
\text { fomento }\end{array}$ & $\begin{array}{l}\text { Precio alquiler, } \\
\text { canon o cesión } \\
\text { de uso }\end{array}$ & $\begin{array}{l}\text { Forma de } \\
\text { adjudicación }\end{array}$ & $\begin{array}{l}\text { Requisitos } \\
\text { destinatarios }\end{array}$ & $\begin{array}{l}\text { Financiación } \\
\text { pública/costes }\end{array}$ & $\begin{array}{l}\text { Titular del } \\
\text { inmueble }\end{array}$ & $\begin{array}{l}\text { Tiempo en que esa } \\
\text { vivienda será de } \\
\text { alquiler social }\end{array}$ \\
\hline $\begin{array}{l}\text { La cesión voluntaria } \\
\text { del uso de viviendas }\end{array}$ & $\begin{array}{l}\text { Según convenio } \\
\text { (en general, } 150 \\
\text { euros de media, sin } \\
\text { superar } 30 \% \text { ingre- } \\
\text { sos netos del hogar) }\end{array}$ & $\begin{array}{l}\text { Prioridad Mesa de } \\
\text { Emergencias }\end{array}$ & $\begin{array}{l}\text { Personas en } \\
\text { situación de } \\
\text { exclusión residen- } \\
\text { cial o en riesgo de } \\
\text { exclusión }\end{array}$ & $\begin{array}{l}\text { Contraprestación } \\
\text { mensual a la propie- } \\
\text { dad según convenio } \\
\text { (entre } 75 \text { y } 150 \text { euros } \\
\text { por vivienda) }\end{array}$ & $\begin{array}{l}\text { Propiedad privada } \\
\text { S }\end{array}$ & $\begin{array}{l}\text { Según convenio } \\
\text { (entre } 5 \text { y } 8 \text { años) }\end{array}$ \\
\hline $\begin{array}{l}\text { La cesión obligatoria } \\
\text { del uso de viviendas }\end{array}$ & $\begin{array}{l}10 \%, 12 \% \text { o } 18 \% \\
\text { de los ingresos } \\
\text { ponderados de la } \\
\text { unidad familiar según } \\
\text { estos sean inferiores } \\
\text { a } 0,89 \text { IRSC, } 0,95 \\
\text { IRSC o superiores }\end{array}$ & $\begin{array}{l}\text { Mediante el fondo } \\
\text { de alquiler para } \\
\text { políticas sociales }\end{array}$ & $\begin{array}{l}\text { Personas en situ- } \\
\text { ación de exclusión } \\
\text { residencial o en } \\
\text { riesgo de exclusión }\end{array}$ & $\begin{array}{l}\text { En ausencia de } \\
\text { acuerdo, compensa- } \\
\text { ción del } 40 \% \text { de la } \\
\text { renta máxima de una } \\
\text { vivienda protegida de } \\
\text { régimen especial }\end{array}$ & Propiedad privada & $\begin{array}{l}\text { Cesión por un periodo } \\
\text { de } 3 \text { años }\end{array}$ \\
\hline $\begin{array}{l}\text { El alquiler social } \\
\text { voluntario }\end{array}$ & $\begin{array}{l}\text { Con carácter general, } \\
\text { un } 25 \% \text { inferior a la } \\
\text { media del mercado } \\
\text { (límite entre } 225 \text {, } \\
300 \text { y } 400 \text { euros/ } \\
\text { mes según municipio, } \\
\text { Orden GAH/16/2017) }\end{array}$ & $\begin{array}{l}\text { No existe proceso } \\
\text { específico de adju- } \\
\text { dicación }\end{array}$ & $\begin{array}{l}\text { Ingresos inferiores } \\
\text { a los establecidos } \\
\text { para acceder a una } \\
\text { vivienda protegida }\end{array}$ & $\begin{array}{l}\text { Bonificación del } \\
\text { impuesto de vivien- } \\
\text { das vacías }\end{array}$ & Propiedad privada & $\begin{array}{l}\text { Duración contrato } \\
\text { alquiler }\end{array}$ \\
\hline $\begin{array}{l}\text { El alquiler social } \\
\text { obligatorio }\end{array}$ & $\begin{array}{l}10 \%, 12 \% \text { o } 18 \% \\
\text { de los ingresos pon- } \\
\text { derados de la unidad } \\
\text { familiar según estos } \\
\text { sean inferiores a } \\
0,89 \text { IRSC, } 0,95 \text { IRSC } \\
\text { o superiores }\end{array}$ & $\begin{array}{l}\text { No existe proceso } \\
\text { de adjudicación pro- } \\
\text { piamente dicho } \\
\text { (la normativa deter- } \\
\text { mina las personas } \\
\text { que tienen este } \\
\text { derecho) }\end{array}$ & $\begin{array}{l}\text { Personas sin una } \\
\text { alternativa residen- } \\
\text { cial y en riesgo de } \\
\text { exclusión residencial } \\
\text { (según definición } \\
\text { normativa) en deter- } \\
\text { minadas situaciones }\end{array}$ & $\begin{array}{l}\text { Ningún coste público } \\
\text { directo }\end{array}$ & Propiedad privada & $\begin{array}{l}5 \text { años (titular } \\
\text { persona física) o } 7 \\
\text { años (titular persona } \\
\text { jurídica) } \\
\text { Derecho a una reno- } \\
\text { vación del contrato si } \\
\text { reúne requisitos }\end{array}$ \\
\hline $\begin{array}{l}\text { La expropiación for- } \\
\text { zosa uso y dominio }\end{array}$ & $\begin{array}{l}10 \%, 12 \% \text { o } 18 \% \\
\text { de los ingresos pon- } \\
\text { derados de la unidad } \\
\text { familiar según estos } \\
\text { sean inferiores a } \\
0,89 \text { IRSC, } 0,95 \text { IRSC } \\
\text { o superiores }\end{array}$ & $\begin{array}{l}\text { No existe proceso } \\
\text { de adjudicación } \\
\text { específico (proce- } \\
\text { dimiento de adjudi- } \\
\text { cación genérico de } \\
\text { la vivienda pública, } \\
\text { y Mesa de Emer- } \\
\text { gencias) }\end{array}$ & $\begin{array}{l}\text { Preferentemente } \\
\text { personas en situación } \\
\text { de exclusión residen- } \\
\text { cial o en riesgo de } \\
\text { exclusión }\end{array}$ & $\begin{array}{l}\text { Justiprecio (el con- } \\
\text { tenido de derecho } \\
\text { - de propiedad debe } \\
\text { reducirse un } 50 \% \\
\text { y hay que tener en } \\
\text { cuenta los criterios } \\
\text { de alquiler social) }\end{array}$ & Titularidad pública & $\begin{array}{l}\text { Forma indefinida } \\
\text { (mientras la Adminis- } \\
\text { tración la destine a } \\
\text { vivienda social) }\end{array}$ \\
\hline $\begin{array}{l}\text { La expropiación } \\
\text { temporal del uso }\end{array}$ & $\begin{array}{l}10 \%, 12 \% \text { o } 18 \% \\
\text { de los ingresos pon- } \\
\text { derados de la unidad } \\
\text { familiar según estos } \\
\text { sean inferiores a } \\
0,89 \text { IRSC, } 0,95 \\
\text { IRSC o superiores }\end{array}$ & $\begin{array}{l}\text { No existe proceso } \\
\text { de adjudicación } \\
\text { específico (proce- } \\
\text { dimiento de adjudi- } \\
\text { cación genérico de } \\
\text { la vivienda pública, } \\
\text { y Mesa de Emer- } \\
\text { gencias) }\end{array}$ & $\begin{array}{l}\text { Preferentemente } \\
\text { personas en situación } \\
\text { de exclusión residen- } \\
\text { cial o en riesgo de } \\
\text { exclusión }\end{array}$ & $\begin{array}{l}\text { Justiprecio (del cual } \\
\text { se deduce el coste } \\
\text { - de las obras para } \\
\text { adecuar la vivienda } \\
\text { a normativa habita- } \\
\text { bilidad) }\end{array}$ & Propiedad privada & $\begin{array}{l}\text { Mínimo } 4 \text { años, } \\
\text { máximo } 10 \text { años }\end{array}$ \\
\hline Las viviendas $60 / 40$ & $\begin{array}{l}10 \%, 12 \% \text { o } 18 \% \text { de } \\
\text { los ingresos ponde- } \\
\text { rados de la unidad } \\
\text { familiar según estos } \\
\text { sean inferiores a } \\
0,89 \text { IRSC, } 0,95 \text { IRSC } \\
\text { o superiores }\end{array}$ & $\begin{array}{l}\text { Mesa de valoración } \\
\text { de situaciones de } \\
\text { emergencias econó- } \\
\text { micas y sociales }\end{array}$ & $\begin{array}{l}\text { Personas y unidades } \\
\text { familiares en riesgo } \\
\text { de exclusión resi- } \\
\text { dencial y en proceso } \\
\text { de desahucio de su } \\
\text { vivienda }\end{array}$ & $\begin{array}{l}\text { La AVC aporta el } \\
60 \% \text { del alquiler } \\
\text { (límite de } 3.000 \text { o } \\
4.500 \text { euros anuales), } \\
\text { resto administración } \\
\text { local }\end{array}$ & Propiedad privada & $\begin{array}{l}\text { Contrato alquiler de } 1 \\
\text { año prorrogable obli- } \\
\text { gatorio hasta } 5 \text { años } \\
\text { Contrato de cesión } \\
\text { de uso por } 2 \text { años } \\
\text { (el } 2^{\circ} \text { año se revisan } \\
\text { las condiciones } \\
\text { económicas y patri- } \\
\text { moniales) }\end{array}$ \\
\hline
\end{tabular}

Fuente: elaboración propia. 


\section{Conclusiones y discusión}

Las nuevas formas de fomento de la vivienda de alquiler social que durante el periodo 2015-2020 ha impulsado el Gobierno catalán se caracterizan por tres aspectos: (i) se centran en atender las necesidades residenciales de la emergencia habitacional surgida tras la crisis de 2008; (ii) promueven la generación de nueva vivienda de alquiler social en el parque existente (a diferencia de otras experiencias innovadoras europeas orientadas a la construcción de nuevas unidades mediante soluciones híbridas publicoprivadas); (iii) y son instrumentos fundamentalmente de carácter normativo, es decir, se sustentan en un marco jurídico que, sobre el principio de la función social de la propiedad residencial, otorga nuevas potestades a la Administración para intervenir en el mercado, y mayores deberes y obligaciones a los propietarios (el programa de vivienda 60/40 es la única excepción en este sentido).

Tras analizar las viviendas obtenidas mediante dichos instrumentos desde las principales variables que caracterizan el concepto de vivienda de alquiler social en Europa, se observa que: (i) su renta mensual es siempre inferior a la del mercado y, en la mayoría de los casos, el grado de asequibilidad es elevado puesto que su coste se calcula en función de los ingresos del hogar; (ii) la adjudicación de casi todas estas viviendas sigue un proceso administrativo determinado (el alquiler social voluntario y el obligatorio son las únicas excepciones); (iii) siempre existen unos criterios de elegibilidad que deben cumplir las personas destinarias de dichas viviendas; (iv) la práctica totalidad de estas medidas lleva asociado un determinado gasto público por vivienda (excepto en el alquiler social obligatorio); (v) y, por lo general, se trata de viviendas de titularidad privada que se destinarán a fines sociales durante un periodo de tiempo determinado. Por consiguiente, todas estas nuevas viviendas, excepto las de alquiler social voluntario u obligatorio, encajarían conceptualmente en las definiciones menos exigentes de vivienda de alquiler social, como las formuladas por CECODHAS-Housing Europe (UNECE, 2003; Czischke, 2007) o la OECD (Andrews et al., 2011; OECD, 2015), puesto que dichas definiciones solo contemplan algunos de los siguientes requisitos: (i) un precio inferior al del mercado, (ii) la existencia de unas normas de adjudicación; (iii) y unas determinadas condiciones socioeconómicas o de vulnerabilidad de las personas beneficiarias. Y, por el contrario, solamente las obtenidas mediante tanteo y retracto o con la institución expropiatoria podrían considerarse viviendas de alquiler social, según Harloe (1995), ya que son las únicas cuya titularidad recae sobre el sector público o entidades sin ánimo de lucro o de lucro limitado.

Asimismo, resulta particularmente interesante constatar la existencia de una estrecha relación entre el coste público asociado al instrumento, la titularidad del inmueble y el tiempo en que la vivienda cumplirá una función social. Como decíamos, solamente las viviendas obtenidas con el tanteo y retracto o mediante la expropiación de su uso y dominio pasan a ser de titularidad pública, lo que elimina cualquier restricción temporal de su uso como vivienda de alquiler social, pero el coste económico asociado es muy superior al necesario 
para generar una vivienda de alquiler social de titularidad privada que, en muchos casos, solo se destinará a este fin durante cinco o siete años. Por todo ello, pese a la bondad de estas medidas de fomento (y de los objetivos que persiguen), es difícil pensar que por sí solas puedan tener un impacto cuantitativamente significativo a largo plazo en la oferta de vivienda de alquiler social en Cataluña si no se complementan con medidas e incentivos adicionales.

Por último, hay que subrayar que, con el fin de poder perfeccionar estos instrumentos, mejorar su programación a largo plazo y maximizar su impacto social, sería conveniente ampliar el conocimiento de los mismos, como mínimo, desde tres líneas de investigación: (i) en el campo económico, a través de estudios comparados de coste-beneficio de estas medidas; (ii) de las necesidades existentes y futuras, tanto en términos cuantitativos como cualitativos, en particular, de los perfiles socioeconómicos asociados; (iii) y del volumen y las características del segmento del parque residencial susceptible de ser objeto de estos instrumentos.

\section{Referencias bibliográficas}

Agència de l'Habitatge de Catalunya (2016). Memòria de l'Agència de l'Habitatge de Catalunya 2015. Barcelona: Generalitat de Catalunya. Departament de Territori i Sostenibilitat y Agència de l'Habitatge de Catalunya [en línea]. Recuperado de $<$ http://agenciahabitatge.gencat.cat/wps/wcm/connect/642af0c8-0d71-4430-8d82-f7f2729c7a0b/MEM\%C3\%92RIA+2015+-+DEF2. pdf?MOD=AJPERES $>$ [consulta: 24 de abril de 2020] .

- (2017). Llibre de procediments. Procediment adjudicació d'habitatges. Codi: P002v8, Data: 22/02/2017 [en línea]. Recuperado de <http://agenciahabitatge.gencat.cat/ wps/wcm/connect/b49d9544-883c-4276-91f0-f888b29caa8a/P002v7\%2BAdjudicaci\%C3\%B3\%2Bd'Habitatges.pdf?MOD=AJPERES> [consulta: 24 de abril de 2020].

- (2019). Memòria 2018. Barcelona: Generalitat de Catalunya. Departament de Territori i Sostenibilitat y Agència de l'Habitatge de Catalunya [en línea]. Recuperado de <http://agenciahabitatge.gencat.cat/wps/wcm/connect/ 9c12a182-52f4-41d8-81ba-8f0c758ff078/Mem\%C3\%B2ria+AHC+2018.pdf?$\mathrm{MOD}=\mathrm{AJPERES}>$ [consulta: 24 de abril de 2020].

AMNISTÍA INTERNACIONAL ESPAÑa (2015). Derechos desalojados. El derecho a la vivienda y los desalojos hipotecarios en España. Madrid: Amnistía Internacional España.

ANDREWS, Dan; CALDERA, Aida y JoHANSSON, Åsa (2011). Housing markets and structural policies in OECD countries. OECD Economics Department Working Papers 836. París: OECD Publishing. <http://dx.doi.org/10.1787/5kgk8t2k9vf3-en>

Baptista, Isabel; Benjaminsen, Lars y Pleace, Nicholas (2015). Local Connection: Rules and Access to Homelessness Services in Europe. EOH Comparative Studies on Homelessness. Bruselas: European Observatory on Homelessness, FEANTSA.

Boelhouwer, Peter y Heijden, Harry van der (1994). «Social housing in Western Europe in the nineties». Journal of Housing and the Built Environment, 9, 331-342. $<$ https://doi.org/10.1007/bf02496523>

BORTEL, Gerard von y GrUIS, Vincent (2019). «Innovative Arrangements between Public and Private Actors in Affordable Housing Provision: Examples from Austria, England and Italy». Urban Science, 3 (2), 52. $<$ https://doi.org/10.3390/urbansci3020052> 
BosCH, Jordi (2017). «La dimensión económica de la exclusión residencial: Cataluña en el contexto europeo". ACE: Architecture, City and Environment, 12 (34), 69-96. <https://doi.org/10.5821/ace.12.34.4695>

Braga, Michela y Palvarini, Pietro (2013). Social Housing in the EU. Bruselas: Directorate-General for Internal Policies, Policy Department.

CARUSO, Nadia (2013). «New practices of social housing: from a definition to recent development». Planum, The Journal of Urbanism, 27 (2), 33-39.

Czischke, Darinka (2007). Current Developments in Housing Policies and Housing Markets in Europe: Implications for the Social Housing Sector. Bruselas: European Social Housing Observatory, CECODHAS.

Czischke, Darinka y PiTTini, Alice (2007). Housing Europe 2007. Review of social, co-operative and public housing in the $27 \mathrm{EU}$ member states. Bruselas: European Social Housing Observatory, CECODHAS.

Departament de Territori i Sostenibilitat (2019a). Pla Territorial Sectorial d'Habitatge. Text de la proposta de decret. Barcelona: Generalitat de Catalunya [en línea]. Recuperado de <https://territori.gencat.cat/web/.content/home/01_ departament/transparencia_i_bon_govern/procediments_i_actuacions_juridiques/normativa_en_tramit/projectes_decret/decret_pla_territorial_sectorial_habitatge/20190304_proposta_disposicio_sigov.pdf $>$ [consulta: 17 de enero de 2021].

- (2019b). Informe sobre el sector de l'habitatge a Catalunya. Any 2018. Barcelona: Generalitat de Catalunya. [en línea]. Recuperado de <http://habitatge.gencat.cat/ web/.content/home/dades/estadistiques/03_Informe_sobre_el_sector_de_1_habitatge_a_Catalunya/informe_sobre_el_sector_de_lhabitatge_a_catalunya/docs/ Informe_2018.pdf> [consulta: 24 de abril de 2020].

FERri, Giordana; POGLIANI, Laura y RIZZICA, Chiara (2019). «Towards a collaborative way of living: innovating social and affordable housing in Italy». En: BORTEL, Gerard van; Gruis, Vincent; Nieuwenhuijzen, Joost y Pluijmers, Ben (eds). Affordable Housing Governance and Finance: Innovations, Partnerships and Comparative Perspectives. Abingdon: Routledge, 59-86. <https://doi.org/10.1201/9781315112350-4>

Granath-Hansson, Anna y Lundgren, Björn (2019). «Defining Social Housing: A Discussion on the Suitable Criteria». Housing, Theory and Society, 36 (2), 149-166. <http://dx.doi.org/10.1080/14036096.2018.1459826>

HarloE, Michael (1995). The people's home? Social rented housing in Europe and America. Oxford: Blackwell.

HeIjDEN, Harry (2002). «Social Rented Housing in Western Europe: Developments and Expectations». Urban Studies, 39 (2), 327-340. <https://doi.org/10.1080/00420980120102993>

HeINO, Jouko; CZISCHKE, Darinka y NiKOlovA, Mariya (2007). Managing social rental housing in the European Union: Experiences and innovative approaches. Helsinki: European Social Housing Observatory, CECODHAS.

HOEKSTRA, Joris (2013). Affordable rental housing produced by private rental landlords: The case of France. Leicester: Montfort University, Centre for Comparative Housing Research y Places for People.

Laino, Elsa y PitTini, Alice (2011). Housing Europe Review 2012. The nuts and bolts of European social housing systems. Bruselas: European Social Housing Observatory, CECODHAS. 
Mattinson, Deborah; Knox, Anastasia; Downes, Nick; Nichols, Catrin; STEeg, Sanne van der; WiLSON, David; LANGDALE, Eleanor y RoBinsOn, Andrew (2019). Social housing in England after Grenfell. Londres: BritainThinks.

MÉNDEZ, Ricardo (2017). «De la hipoteca al desahucio: ejecuciones hipotecarias y vulnerabilidad territorial en España». Revista de Geografía Norte Grande, 67, 9-31. <http://dx.doi.org/10.4067/S0718-34022017000200002>

MÉNDEZ, Ricardo y PlAZA, Julio (2016). "Crisis inmobiliaria y desahucios hipotecarios en España: una perspectiva geográfica». Boletín de la Asociación de Geógrafos Españoles, 71, 99-127. <https://doi.org/10.21138/bage.2276>

Milligan, Vivienne y Gilmour, Tony (2012). «Affordable Housing Strategies». En: Smith, Susan; Elsinga, Marja; O’Mahony, Lorna Fox; Eng, Ong Seow; WaCHTER, Susan y TSENKOVA, Sasha (eds). International Encyclopedia of Housing and Home. Oxford: Elsevier, 58-64. <http://dx.doi.org/10.1016/B978-0-08-047163-1.00396-9>

MundT, Alexis y AMAnN, Wolfgang (2018). "Wiener Wohnbauinitiative”: a new financing vehicle for affordable housing in Vienna, Austria». En: BORTEL, Gerard van; Gruis, Vincent; Nieuwenhuijzen, Joost y Pluijmers, Ben (eds). Affordable Housing Governance and Finance: Innovations, Partnerships and Comparative Perspectives. Abingdon: Routledge, 187-208. <https://doi.org/10.1201/9781315112350-10>

ODESC/PAH (2016). Exclusión residencial en el mundo local. Informe de la crisis hipotecaria en Barcelona (2013-2016). Barcelona: Observatorio Derechos Humanos DESC y Plataforma de Afectados por la Hipoteca.

- (2018). Radiografies de la situació del dret a l'habitatge, la pobresa energètica i el seu impacte en la salut a Barcelona. Informe II. Perspectiva de gènere sobre el dret a l'habitatge i la pobresa energètica a Barcelona. Barcelona: Observatorio Derechos Humanos DESC y Plataforma de Afectados por la Hipoteca.

OECD (2015). Integrating Social Services for Vulnerable Groups: Bridging Sectors for Better Service Delivery. París: OECD Publishing. <https://doi.org/10.1787/9789264233775-en>

- (2019). PH4.3 Key Characteristics of Social Rental Housing. OECD Affordable Housing Database. OECD - Social Policy Division - Directorate of Employment, Labour and Social Affairs [en línea]. Recuperado de <https://www.oecd.org/els/family/ PH4-3-Characteristics-of-social-rental-housing.pdf> [consulta: 24 de abril de 2020].

OxLEY, Michael (2009). Financing Affordable Social Housing in Europe. Nairobi: UN-Habitat.

Pittini, Alice; Koessl, Gerald; Dijol, Julien; LaKatos, Edit y GHeKiÈre, Laurent (2017). The State of Housing in the EU 2017. Bruselas: European Social Housing Observatory, CECODHAS.

Pittini, Alice; Dijol, Julien; Turnbull, Dara y Whelan, Mariel (2019). The State of Housing in the EU 2019. Bruselas: European Social Housing Observatory, CECODHAS.

Pleace, Nicholas; Teller, Nora y Quilgars, Deborah Jayne (2011). Social Housing Allocation and Homelessness: EOH Comparative Studies on Homelessness. Bruselas: FEANTSA.

Priemus, Hugo y Boelhouwer, Peter (1998). «Social Housing Finance in Europe: Trends and Opportunities». Urban Studies, 36 (4), 633-645. <http://dx.doi.org/10.1080/0042098993367> 
SALA, Eduard (2018). «Análisis geográfico de la crisis hipotecaria: la distribución desigual a diferentes escalas». Biblio 3w: Revista Bibliográfica de Geografía y Ciencias Sociales, 23 (1.256), 1-24. <https://doi.org/10.1344/b3w.0.2018.27249>

UNECE (2003). Social Housing in the UNECE Region. Discussion paper, prepared by the UNECE secretariat in cooperation with the European Liaison Committee for Social Housing (CECODHAS). Praga: UNECE y CECODHAS.

United Nations (2006). Guidelines on Social Housing. Principles and Examples. Ginebra: United Nations Publications. 
